\title{
Farsightedly stable networks
}

Citation for published version (APA):

Herings, P. J. J., Mauleon, A., \& Vannetelbosch, V. (2006). Farsightedly stable networks. METEOR, Maastricht University School of Business and Economics. METEOR Research Memorandum No. 041 https://doi.org/10.26481/umamet.2006041

Document status and date:

Published: 01/01/2006

DOI:

10.26481/umamet.2006041

Document Version:

Publisher's PDF, also known as Version of record

\section{Please check the document version of this publication:}

- A submitted manuscript is the version of the article upon submission and before peer-review. There can be important differences between the submitted version and the official published version of record.

People interested in the research are advised to contact the author for the final version of the publication, or visit the DOI to the publisher's website.

- The final author version and the galley proof are versions of the publication after peer review.

- The final published version features the final layout of the paper including the volume, issue and page numbers.

Link to publication

\footnotetext{
General rights rights.

- You may freely distribute the URL identifying the publication in the public portal. please follow below link for the End User Agreement:

www.umlib.nl/taverne-license

Take down policy

If you believe that this document breaches copyright please contact us at:

repository@maastrichtuniversity.nl

providing details and we will investigate your claim.
}

Copyright and moral rights for the publications made accessible in the public portal are retained by the authors and/or other copyright owners and it is a condition of accessing publications that users recognise and abide by the legal requirements associated with these

- Users may download and print one copy of any publication from the public portal for the purpose of private study or research.

- You may not further distribute the material or use it for any profit-making activity or commercial gain

If the publication is distributed under the terms of Article $25 \mathrm{fa}$ of the Dutch Copyright Act, indicated by the "Taverne" license above, 
P. Jean-Jacques Herings, Ana Mauleon, Vincent Vannetelbosch

Farsightedly Stable Networks

RM/06/041

JEL code: A14, C70, D20

Maastricht research school of Economics of TEchnology and ORganizations

Universiteit Maastricht

Faculty of Economics and Business Administration P.O. Box 616

NL - 6200 MD Maastricht

phone : ++31433883830

fax $\quad$ : ++31433884873 



\title{
Farsightedly Stable Networks*
}

\author{
P. Jean-Jacques Herings \\ Department of Economics, \\ Maastricht University.
}

\author{
Ana Mauleon \\ FNRS and CEREC, FUSL, \\ and CORE, UCL.
}

Vincent Vannetelbosch

FNRS and CORE, UCL.

September 21, 2006

\begin{abstract}
We propose a new concept, the pairwise farsightedly stable set, in order to predict which networks may be formed among farsighted players. A set of networks $G$ is pairwise farsightedly stable (i) if all possible pairwise deviations from any network $g \in G$ to a network outside $G$ are deterred by the threat of ending worse off or equally well off, (ii) if there exists a farsightedly improving path from any network outside the set leading to some network in the set, and (iii) if there is no proper subset of $G$ satisfying (i) and (ii). We show that a non-empty pairwise farsightedly stable set always exists and we provide a full characterization of unique pairwise farsightedly stable sets of networks. Contrary to other pairwise concepts, pairwise farsighted stability yields a Pareto dominating network, if it exists, as the unique outcome. Finally, we study the relationship between pairwise farsighted stability and other concepts such as the largest consistent set.
\end{abstract}

JEL classification: A14, C70, D20.

Keywords: Networks, Farsighted, Stability, Pairwise, Efficiency.

\footnotetext{
${ }^{*}$ Corresponding author: Prof. Vincent Vannetelbosch, CORE, University of Louvain, 34 voie du Roman Pays, B-1348 Louvain-la-Neuve, Belgium (e-mail: vannetelbosch@core.ucl.ac.be)
} 


\section{Introduction}

The organization of individual agents into networks and groups or coalitions plays an important role in the determination of the outcome of many social and economic interactions. For instance, networks of personal contacts are important in obtaining information about job opportunities. Goods can be traded and exchanged through networks of buyers and sellers. The partitioning of societies into groups is also important in many contexts, such as the provision of public goods and the formation of alliances, cartels and federations. ${ }^{1}$

A simple way to analyze the networks that one might expect to emerge in the long run is to examine the requirement that individuals do not benefit from altering the structure of the network. A weak version of such a condition is the pairwise stability notion defined by Jackson and Wolinsky (1996). There are alternative ways to model network stability. One is to explicitly model a game by which links form and then to solve that game using the concept of Nash equilibrium or one of its refinements. Aumann and Myerson (1988) take such an approach in the context of communication games, where individuals sequentially propose links. However, such an approach has the disadvantage that the game is necessarily ad hoc and is quite sensitive to the exact network formation process.

Dutta and Mutuswami (1997) analyze a link formation game where individuals simultaneously choose all the links they wish to be involved in. But this approach is static and myopic. Individuals cannot be forward-looking in the sense that they do not forecast how others might react to their actions. For instance, individuals might not add a link that appears valuable to them given the current network, as that might in turn lead to the formation of other links and ultimately lower the payoffs of the original individuals.

A dynamic (but still myopic) network formation process has been recently studied by Jackson and Watts (2002), who have proposed a dynamic process in which individuals form and sever links based on the improvement that the resulting network offers them relative to the current network. This deterministic dynamic process may end at stable networks or in some cases may cycle. ${ }^{2}$

We propose a new concept, pairwise farsightedly stable set, in order to predict which networks may be formed among farsighted players. A set of networks $G$ is pairwise farsightedly stable (i) if all possible pairwise deviations from any network $g \in G$ are deterred by the threat of ending worse off or equally well off, (ii) if there exists a farsightedly improving path from any network outside the set leading to some network in the set, and (iii) if there is no proper subset of $G$ satisfying (i) and (ii). In contrast to other concepts incor-

\footnotetext{
${ }^{1}$ Jackson $(2003,2005)$ provides surveys of models of network formation.

${ }^{2}$ Watts (2001) has extended the Jackson and Wolinsky model to a dynamic process but she has limited attention to the context of the connections model and a particular deterministic dynamic.
} 
porating farsightedness, we propose a set-valued concept which not only requests that all possible pairwise deviations out of the set are deterred by the threat of ending worse off, but also that the networks within the set are robust to perturbations. Unintended changes may be due to exogenous forces acting on the network, or simply miscalculations or errors on the part of an individual making an assessment or taking an action. Robustness to perturbations asks for the existence of a farsightedly improving path from any network outside the set leading to some network in the set. ${ }^{3}$

A farsightedly improving path is a sequence of networks that can emerge when players form or sever links based on the improvement the end network offers relative to the current network. Each network in the sequence differs by one link from the previous one. If a link is added, then the two players involved must both prefer the end network to the current network, with at least one of the two strictly preferring the end network. If a link is deleted, then it must be that at least one of the two players involved in the link strictly prefers the end network. We show that a pairwise farsightedly stable set always exists and we provide a full characterization of unique pairwise farsightedly stable sets of networks. As a corollary, we give the necessary and sufficient condition such that a unique pairwise farsightedly stable set consisting of a single network exists.

We also look at the relationship between farsighted stability and efficiency of networks. We find that the pairwise farsightedly stable sets and the set of strongly efficient networks, those which are socially optimal, may be disjoint. We provide conditions on the allocation rule and the value function such that pairwise farsighted stability singles out the strongly efficient network. Contrary to other pairwise concepts, if there is a network that Pareto dominates all other networks, then that network is the unique prediction of pairwise farsighted stability.

Finally, we study the relationship between pairwise farsightedly stability and other concepts such as the pairwise largest consistent set, a notion due to Chwe (1994). By means of examples we show that there is no relationship between (i) pairwise farsightedly stable sets and pairwise largest consistent sets, (ii) pairwise farsightedly stable sets and pairwise stability. Indeed, the pairwise stable networks may not belong to any pairwise farsightedly stable set of networks.

Although the literature on stability in networks is well established and growing (see Jackson, 2005), the literature on farsighted stability is still in its infancy. Page, Wooders and Kamat (2005) have addressed the issue of farsighted stability in network formation

\footnotetext{
${ }^{3}$ Jackson and Watts (2002) use improving paths as the foundation for a stochastic analysis, where in addition to intended changes in the network, unintended mutations or errors are introduced. However, in their definition of improving path it is assumed that players behave myopically: all a player needs to know is whether adding or deleting a given link is directly beneficial to him or her in the current circumstances.
} 
by extending Chwe's (1994) result on the nonemptiness of farsightedly consistent sets. In order to demonstrate the existence of farsightedly consistent directed networks, they have provided a new framework that extends the standard notion of a directed network and also introduces the notion of a supernetwork. A supernetwork specifies how the different directed networks are connected via coalitional moves and coalitional preferences, and thus provides a network representation of agent preferences and the rules governing network formation (that is, a supernetwork is equivalent to the social environment studied by Chwe (1994), where the set of outcomes is replaced by the set of directed networks). Given the rules governing network formation and agents preferences as represented via the supernetwork, a directed network (i.e., a particular node in the supernetwork) is said to be farsightedly consistent if no agent or coalition of agents is willing to alter the network (via the addition, subtraction, or replacement of arcs) in fear that such an alteration might induce further network alterations by other agents or coalitions that in the end leave the initially deviating agent or coalition no better off, and possibly worse off. They have shown that for any supernetwork corresponding to a given collection of directed networks, the set of farsightedly consistent networks is nonempty; see also Page and Wooders (2005). Dutta, Ghosal and Ray (2005) have studied a model of dynamic network formation where individuals are farsighted and evaluate the desirability of a move in terms of its consequences on the entire discounted stream of payoffs. Only special coalitions are active at any date. They have shown that a Markovian equilibrium process of network formation exists and that there are valuation structures in which no equilibrium strategy profile yields paths that are absorbed solely into a set of efficient networks. This can be viewed as the dynamic counterpart of the conflict between (static) stability and efficiency demonstrated by Jackson and Wolinsky (1996). They provide two conditions on the valuation structure that guarantee that there is some equilibrium profile at which the complete graph is reached in the limit from all initial networks. ${ }^{4}$

The paper is organized as follows. In Section 2 we introduce some notations and basic properties and definitions for networks. In Section 3 we define the notion of pairwise farsightedly stable set of networks and we study its properties. In Section 4 we look at the relationship between farsighted stability and efficiency of networks. In Section 5 we analyze the relationship between pairwise farsightedly stable set of networks and the pairwise largest consistent set. In Section 5 we conclude.

\footnotetext{
${ }^{4}$ Other approaches to farsightedness in network formation are suggested by the work of Xue (1998), Herings, Mauleon and Vannetelbosch (2004), and Mauleon and Vannetelbosch (2004).
} 


\section{Networks}

Let $N=\{1, \ldots, n\}$ be the finite set of players who are connected in some network relationship. The network relationships are reciprocal and the network is thus modeled as a non-directed graph. Individuals are the nodes in the graph and links indicate bilateral relationships between individuals. Thus, a network $g$ is simply a list of which pairs of individuals are linked to each other. We write $i j \in g$ to indicate that $i$ and $j$ are linked under the network $g$. Let $g^{N}$ be the collection of all subsets of $N$ with cardinality 2, so $g^{N}$ is the complete network. The set of all possible networks or graphs on $N$ is denoted by $\mathbb{G}$. The set $\mathbb{G}$ is the collection of all subsets of $g^{N}$. The network obtained by adding link $i j$ to an existing network $g$ is denoted $g+i j$ and the network that results from deleting link $i j$ from an existing network $g$ is denoted $g-i j$. For any network $g$, let $N(g)=\{i \mid$ there is $j$ such that $i j \in g\}$ be the set of players who have at least one link in the network $g$. A path in a network $g \in \mathbb{G}$ between $i$ and $j$ is a sequence of players $i_{1}, \ldots, i_{K}$ such that $i_{k} i_{k+1} \in g$ for each $k \in\{1, \ldots, K-1\}$ with $i_{1}=1$ and $i_{K}=j$. A nonempty network $h \subseteq g$ is a component of $g$, if for all $i \in N(h)$ and $j \in N(h), i \neq j$, there exists a path in $h$ connecting $i$ and $j$, and for any $i \in N(h)$ and $j \in N(g), i j \in g$ implies $i j \in h$. The set of components of $g$ is denoted by $C(g) .^{5}$

A value function is a function $v: \mathbb{G} \rightarrow \mathbb{R}$ that keeps track of how the total societal value varies across different networks. The set of all possible value functions is denoted $\mathcal{V}$. An allocation rule is a function $Y: \mathbb{G} \times \mathcal{V} \rightarrow \mathbb{R}^{N}$ that keeps track of how the value is allocated or distributed among the players forming a network, and satisfies $\sum_{i \in N} Y_{i}(g, v)=v(g)$ for all $v$ and $g$.

Jackson and Wolinsky (1996) have proposed basic properties of value and allocation functions. A value function is component additive if $v(g)=\sum_{h \in C(g)} v(h)$ for all $g \in \mathbb{G}$. Component additive value functions are the ones for which the value of a network is the sum of the value of its components. An allocation rule $Y$ is component balanced if for any component additive $v \in \mathcal{V}, g \in \mathbb{G}$, and $h \in C(g)$, we have $\sum_{i \in N(h)} Y_{i}(h, v)=v(h)$. Component balancedness only puts conditions on $Y$ for $v$ 's that are component additive, so $Y$ can be arbitrary otherwise. Given a permutation of players $\pi$ and any $g \in \mathbb{G}$, let $g^{\pi}=\{\pi(i) \pi(j) \mid i j \in g\}$. Thus, $g^{\pi}$ is a network that is identical to $g$ up to a permutation of the players. A value function is anonymous if for any permutation $\pi$ and any $g \in \mathbb{G}$, $v\left(g^{\pi}\right)=v(g)$. Given a permutation $\pi$, let $v^{\pi}$ be defined by $v^{\pi}(g)=v\left(g^{\pi^{-1}}\right)$ for each $g \in \mathbb{G}$. An allocation rule $Y$ is anonymous if for any $v \in \mathcal{V}, g \in \mathbb{G}$, and permutation $\pi$, we have

\footnotetext{
${ }^{5}$ Throughout the paper we use the notation $\subseteq$ for weak inclusion and $\varsubsetneqq$ for strict inclusion. Finally, \# will refer to the notion of cardinality.
} 
$Y_{\pi(i)}\left(g^{\pi}, v^{\pi}\right)=Y_{i}(g, v){ }^{6}$

An allocation rule that is component balanced and anonymous is the componentwise egalitarian allocation rule. For a component additive $v$ and network $g$, the componentwise egalitarian allocation rule $Y^{c e}$ is such that for any $h \in C(g)$ and each $i \in N(h), Y_{i}^{c e}(g, v)=$ $v(h) / \# N(h)$. For a $v$ that is not component additive, $Y^{c e}(g, v)=v(g) / n$ for all $g$; thus, $Y^{c e}$ splits the value $v(g)$ equally among all players if $v$ is not component additive.

In evaluating societal welfare, we may take various perspectives. A network $g$ is Pareto efficient relative to $v$ and $Y$ if there does not exist any $g^{\prime} \in \mathbb{G}$ such that $Y_{i}\left(g^{\prime}, v\right) \geq Y_{i}(g, v)$ for all $i$ with at least one strict inequality. A network $g \in \mathbb{G}$ is strongly efficient relative to $v$ if $v(g) \geq v\left(g^{\prime}\right)$ for all $g^{\prime} \in \mathbb{G}$. This is a strong notion of efficiency as it takes the perspective that value is fully transferable.

The network-theoretic literature uses two different notions of a deviation by a coalition. Pairwise deviations (Jackson and Wolinsky, 1996) are deviations involving a single link at a time. Moreover, link addition is bilateral (two players that would be involved in the link must agree to adding the link), link deletion is unilateral (at least one player involved in the link must agree to delete the link), and network changes take place one link at a time. Coalitionwise deviations (Jackson and van den Nouweland, 2005) are deviations involving several links and some group of players at a time. Link addition is bilateral, link deletion is unilateral, and multiple link changes can take place at a time. Whether a pairwise deviation or a coalitionwise deviation makes more sense will depend on the setting within which network formation takes place.

We will restrict our analysis to pairwise deviations. A simple way to analyze the networks that one might expect to emerge in the long run is to examine the requirement that agents do not benefit from altering the structure of the network. A weak version of such a condition is the pairwise stability notion defined by Jackson and Wolinsky (1996). A network is pairwise stable if no player benefits from severing one of their links and no other two players benefit from adding a link between them, with one benefiting strictly and the other at least weakly.

Definition 1 A network $g$ is pairwise stable with respect to value function $v$ and allocation rule $Y$ if

(i) for all $i j \in g, Y_{i}(g, v) \geq Y_{i}(g-i j, v)$ and $Y_{j}(g, v) \geq Y_{j}(g-i j, v)$, and

(ii) for all ij $\notin g$, if $Y_{i}(g, v)<Y_{i}(g+i j, v)$ then $Y_{j}(g, v)>Y_{j}(g+i j, v)$.

\footnotetext{
${ }^{6}$ Anonymous value functions are those such that the architecture of a network matters, but not the labels of individuals. Anonymity of an allocation rule requires that if all that has changed is the labels of the agents and the value generated by networks has changed in an exactly corresponding fashion, then the allocation only changes according to the relabeling.
} 
We say that $g^{\prime}$ is adjacent to $g$ if $g^{\prime}=g+i j$ or $g^{\prime}=g-i j$ for some $i j$. A network $g^{\prime}$ defeats $g$ if either $g^{\prime}=g-i j$ and $Y_{i}\left(g^{\prime}, v\right)>Y_{i}(g, v)$ or $Y_{j}\left(g^{\prime}, v\right)>Y_{j}(g, v)$, or if $g^{\prime}=g+i j$ with $Y_{i}\left(g^{\prime}, v\right) \geq Y_{i}(g, v)$ and $Y_{j}\left(g^{\prime}, v\right) \geq Y_{j}(g, v)$ with at least one inequality holding strictly. Pairwise stability is equivalent to the statement of not being defeated by another network. ${ }^{7}$

\section{Pairwise farsightedly stable sets of networks}

The following example shows that a network that is pairwise stable need not be farsightedly stable.

Example 1 Criminal networks. ${ }^{8}$ Each player is a criminal. If two players are connected, then they are part of the same criminal network. Each group of connected criminals has a positive probability of winning the loot. The loot is divided among the connected criminals based on the network architecture. Criminal $i$ 's payoff is given by

$$
\begin{aligned}
Y_{i}(g) & =p_{i}(g) \cdot\left(y_{i}(g)-\phi\right)+\left(1-p_{i}(g)\right) \cdot y_{i}(g) \\
& =y_{i}(g)-p_{i}(g) \cdot \phi,
\end{aligned}
$$

where $y_{i}(g)$ is $i$ 's expected share of the loot, $p_{i}(g)$ is $i$ 's probability of being caught, $\phi>0$ the monetary equivalent of the penalty. ${ }^{9}$ Beside being competitors in the crime market, criminals may also benefit from having criminal mates. It is assumed that (i) the bigger the group of connected criminals, the higher its probability of getting the loot, and (ii) the higher the number of links a criminal has, the lower his individual probability of being caught. Let $n_{i}$ be the number of links criminal $i$ has. Thus, it is assumed that $p_{i}(g)$ is decreasing in $n_{i}$. A criminal $i$ that is part of a group $S$ expects a share of the loot $B$ given

\footnotetext{
${ }^{7}$ Jackson and van den Nouweland (2005) have proposed a refinement of pairwise stability where coalitionwise deviations are allowed: the strongly stable networks. A strongly stable network is a network which is stable against changes in links by any coalition of individuals. Strongly stable networks are Pareto efficient and maximize the overall value of the network if the value of each component of a network is allocated equally among the members of that component.

${ }^{8}$ This is a simplified version of Calvó-Armengol and Zenou's (2004) model where, in addition to forming links with criminal mates, criminals choose their level of criminal activities and whether or not to be involved in criminal activities.

${ }^{9}$ The value function $v$ is simply $v(g)=\sum_{i \in N} Y_{i}(g)$. Since $v$ is fixed, we omit it in the notation of $Y_{i}(v, g)$.
} 
by

$$
\begin{array}{ll}
y_{i}(g)=\frac{|S|}{n} \cdot \frac{n_{i}}{\sum_{j \in S} n_{j}} \cdot B, & \text { if }|S| \geq 2, \\
y_{i}(g)=\frac{1}{n} \cdot B, & \text { if }|S|=1,
\end{array}
$$

where $|S| / n$ is the probability that group $S$ will win the loot, and $n_{i} \cdot\left[\sum_{j \in S} n_{j}\right]^{-1}$ is the share of the loot criminal $i \in S$ would obtain. ${ }^{10}$ In Figure 1 we have depicted the 3 -player case with $B=6$ and $p_{i}(g)=\left(n-1-n_{i}\right) / n$. For $\phi<\frac{3}{2}$, both the partial networks $\left(g_{1}, g_{2}, g_{3}\right)$ and the complete network $\left(g_{7}\right)$ are pairwise stable networks. For $\phi \geq \frac{3}{2}$, the complete network is the only pairwise stable network.

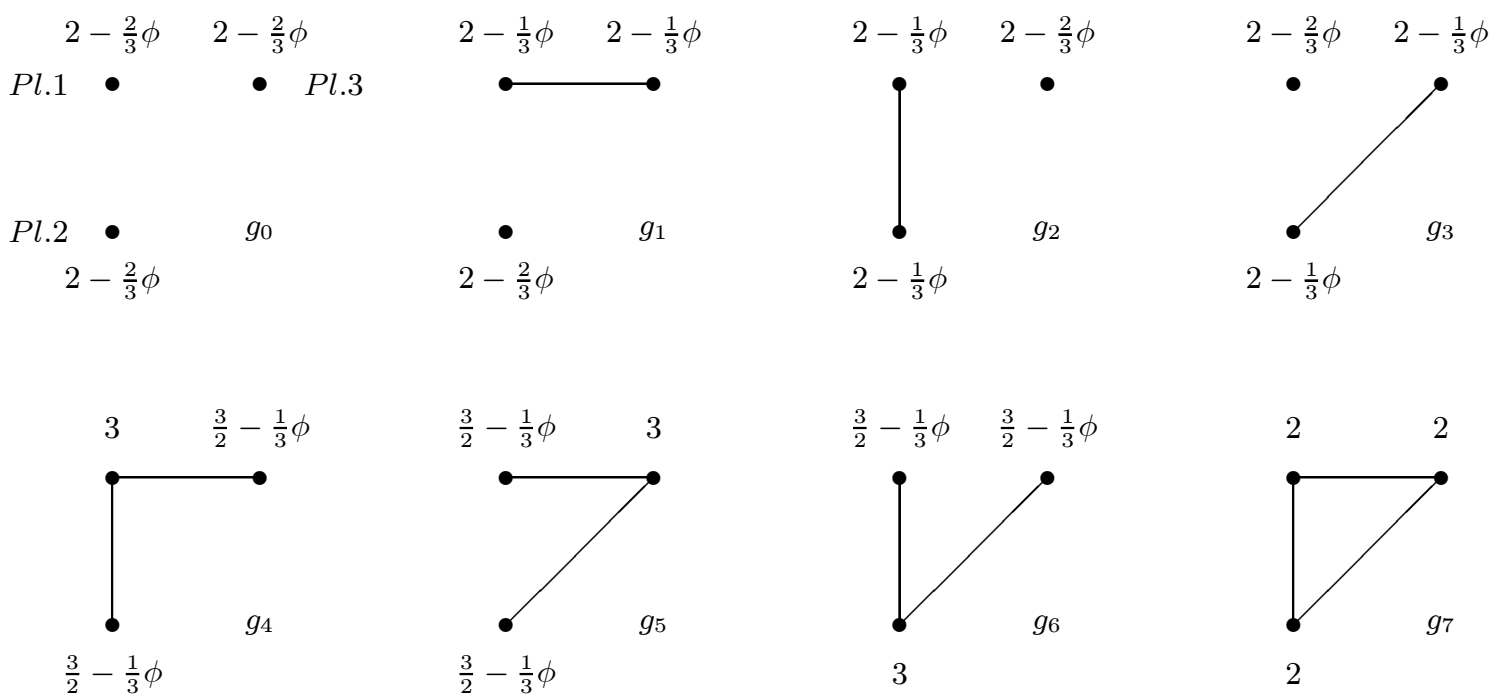

Figure 1: Criminal networks.

Take some $\phi$ smaller than $3 / 2$ in Example 1. Notice that two links have to be added to a partial network $g_{1}, g_{2}$, or $g_{3}$ to form the complete network $g_{7}$. Farsighted players may decide to add one link to a network like $g_{1}, g_{2}$, or $g_{3}$, accepting a loss, in the expectation that a further link will be added to form the complete network. Starting from the complete network, farsighted players will decide not to delete a link in fear of eventually going back to the partial network. A farsightedly improving path is a sequence of networks that can emerge when players form or sever links based on the improvement the end network offers

\footnotetext{
${ }^{10}$ This assumption captures the idea that delinquents learn from other criminals belonging to the same network how to commit crime in a more efficient way by sharing the know-how about the technology of crime (see Calvó-Armengol and Zenou, 2004).
} 
relative to the current network. ${ }^{11}$ Each network in the sequence differs by one link from the previous one. If a link is added, then the two players involved must both prefer the end network to the current network, with at least one of the two strictly preferring the end network. If a link is deleted, then it must be that at least one of the two players involved in the link strictly prefers the end network. We now introduce the formal definition of a farsightedly improving path.

Definition 2 A farsightedly improving path from a network $g$ to a network $g^{\prime}$ is a finite sequence of graphs $g_{1}, \ldots, g_{K}$ with $g_{1}=g$ and $g_{K}=g^{\prime}$ such that for any $k \in\{1, \ldots, K-1\}$ either:

(i) $g_{k+1}=g_{k}-i j$ for some $i j$ such that $Y_{i}\left(g_{K}, v\right)>Y_{i}\left(g_{k}, v\right)$ or $Y_{j}\left(g_{K}, v\right)>Y_{j}\left(g_{k}, v\right)$, or

(ii) $g_{k+1}=g_{k}+i j$ for some $i j$ such that $Y_{i}\left(g_{K}, v\right)>Y_{i}\left(g_{k}, v\right)$ and $Y_{j}\left(g_{K}, v\right) \geq Y_{j}\left(g_{k}, v\right)$.

It follows immediately from the definition that the existence of a farsightedly improving path from $g$ to $g^{\prime}$ implies $g^{\prime} \neq g$.

If there exists a farsightedly improving path from $g$ to $g^{\prime}$, then we write $g \rightarrow g^{\prime}$. For a given network $g$, let $F(g)=\left\{g^{\prime} \in \mathbb{G} \mid g \rightarrow g^{\prime}\right\}$. This is the set of networks that can be reached by a farsightedly improving path from $g$. Thus, $g \rightarrow g^{\prime}$ means that $g^{\prime}$ is the endpoint of at least one farsightedly improving path from $g$.

Suppose in Example 1 with $\phi$ smaller than $3 / 2$ that the starting network $g$ is a partial network, more specifically, $g=g_{1}, g_{2}$, or $g_{3}$. Then, from $g$ no myopic improving path results in the complete network. The problem is that an isolated player will loose from making a link with any of the other players. However, there are farsightedly improving paths that go to the complete network. An example of the sequence of graphs on the farsightedly improving path is $\left(g_{1}, g_{4}, g_{7}\right)$ when starting in $g_{1}$. Similar farsightedly improving paths exist starting in any of the other partial networks. Examples of farsightedly improving paths starting in $g_{1}$ and ending in $g_{7}$ are $\left(g_{1}, g_{4}, g_{7}\right),\left(g_{1}, g_{5}, g_{7}\right)$, or even $\left(g_{1}, g_{0}, g_{2}, g_{6}, g_{7}\right)$. Moreover, from any $g \neq g_{7}$ there is a farsightedly improving path going to $g_{7}$. Thus, we observe that the partial networks are pairwise stable, but not stable when players are farsighted. The complete network on the other hand is not only pairwise stable. It is also stable when players are farsighted.

We now introduce the new concept, pairwise farsightedly stable sets. A set of networks $G$ is pairwise farsightedly stable if (i) all possible pairwise deviations from any network

\footnotetext{
${ }^{11}$ Jackson and Watts (2002) have provided a myopic definition of an improving path. A "myopic" improving path is a sequence of networks that can emerge when players form or sever links based on the improvement the resulting network offers relative to the current network.
} 
$g \in G$ to a network outside $G$ are deterred by a credible threat of ending worse off or equally well off, (ii) there exists a farsightedly improving path from any network outside the set leading to some network in the set, and (iii) there is no proper subset of $G$ satisfying (i) and (ii) (minimality condition). Formally, pairwise farsightedly stable sets are defined as follows.

Definition $3 A$ set of networks $G \subseteq \mathbb{G}$ is pairwise farsightedly stable with respect $v$ and $Y$ if

(i) $\forall g \in G$,

(ia) $\forall i j \notin g$ such that $g+i j \notin G, \exists g^{\prime} \in G \cap F(g+i j)$ such that $\left(Y_{i}\left(g^{\prime}, v\right), Y_{j}\left(g^{\prime}, v\right)\right)=$ $\left(Y_{i}(g, v), Y_{j}(g, v)\right)$ or $Y_{i}\left(g^{\prime}, v\right)<Y_{i}(g, v)$ or $Y_{j}\left(g^{\prime}, v\right)<Y_{j}(g, v)$,

(ib) $\forall i j \in g$ such that $g-i j \notin G, \exists g^{\prime}, g^{\prime \prime} \in G \cap F(g-i j)$ such that $Y_{i}\left(g^{\prime}, v\right) \leq Y_{i}(g, v)$ and $Y_{j}\left(g^{\prime \prime}, v\right) \leq Y_{j}(g, v)$,

(ii) $\forall g^{\prime} \notin G$ we have $g \in F\left(g^{\prime}\right)$ for some $g \in G$,

(iii) $\nexists G^{\prime} \varsubsetneqq G$ such that $G^{\prime}$ satisfies $(\boldsymbol{i a}),(\boldsymbol{i b})$, and $(\boldsymbol{i i})$.

Part (ia) in Definition 3 captures that adding a link $i j$ to a network $g \in G$ that leads to a network outside of $G$, is deterred by the threat of ending in $g^{\prime}$. Here $g^{\prime}$ is such that there is a farsightedly improving path from $g+i j$ to $g^{\prime}$. Moreover, $g^{\prime}$ belongs to $G$, which makes $g^{\prime}$ a credible threat. Part (ib) is a similar requirement, but then for the case where a link is severed. Part (ii) in Definition 3 requires that the networks within the set are robust to perturbations. Robustness to perturbations asks for the existence of a farsightedly improving path from any network outside $G$ leading to some network in G. ${ }^{12}$ Notice that the set $\mathbb{G}$ (trivially) satisfies (ia), (ib), and (ii) in Definition 3. This motivates the requirement of a minimality condition, namely Part (iii). Part (ii) implies that if a set of networks is pairwise farsightedly stable, it is non-empty.

Theorem 1 A pairwise farsightedly stable set of networks exists.

Proof. Notice that $\mathbb{G}$ satisfies (i) and (ii). Let us proceed by contradiction. Assume that there does not exist any set of networks $G \subseteq \mathbb{G}$ that is pairwise farsightedly stable. This means that for any $G^{0} \subseteq \mathbb{G}$ that satisfies (i) and (ii) in Definition 3, we can find

\footnotetext{
${ }^{12}$ There are some random dynamic models of network formation that are based on incentives to form links such as Watts (2001), Jackson and Watts (2002), and Tercieux and Vannetelbosch (2006). These models aim to use the random process to select from the set of pairwise stable networks. Part (ii) in Definition 3 asks for the robustness to perturbations of the set of pairwise farsightedly networks.
} 
a proper subset $G^{1}$ that satisfies (i) and (ii). Iterating this reasoning we can build an infinite decreasing sequence $\left\{G^{k}\right\}_{k \geq 0}$ of elements of $\mathbb{G}$ satisfying (i) and (ii). But since $\mathbb{G}$ has finite cardinality, this is not possible.

In Example 1 with $n=3, B=6$, and $p_{i}(g)=\left(n-1-n_{i}\right) / n$, the set consisting of the complete network is the unique pairwise farsightedly stable set whatever the fine $\phi$.

We consider first the case $\phi<\frac{3}{2}$. It can be verified that $F\left(g_{0}\right)=\left\{g_{1}, g_{2}, g_{3}, g_{7}\right\}$, $F\left(g_{1}\right)=\left\{g_{2}, g_{3}, g_{7}\right\}, F\left(g_{2}\right)=\left\{g_{1}, g_{3}, g_{7}\right\}, F\left(g_{3}\right)=\left\{g_{1}, g_{2}, g_{7}\right\}, F\left(g_{4}\right)=\left\{g_{1}, g_{2}, g_{3}, g_{7}\right\}$, $F\left(g_{5}\right)=\left\{g_{1}, g_{2}, g_{3}, g_{7}\right\}, F\left(g_{6}\right)=\left\{g_{1}, g_{2}, g_{3}, g_{7}\right\}$, and $F\left(g_{7}\right)=\emptyset$. Notice that the analysis of farsightedly improving paths can be intricate. The only way to go from $g_{1}$ to $g_{2}$ is via $g_{4}$. At the same time it holds that $g_{4} \notin F\left(g_{1}\right)$. Indeed, players 1 and 2 make a link to go from $g_{1}$ to the intermediate network $g_{4}$ in the anticipation that player 3 will subsequently delete his link with player 1 . To go from $g_{1}$ to the terminal network $g_{4}$ is a strict deterioration for players 2 and 3 . The only thing player 1 can do is to sever his link with player 2 , which leads to $g_{0}$. This is not helpful for player 1 , since once at $g_{0}$ he is still the only one that is better off at $g_{4}$ compared to $g_{0}$, and there is nothing that he can do anymore.

We show next that $\left\{g_{7}\right\}$ is pairwise farsightedly stable. Since $g_{7} \in \bigcap_{g \in \mathbb{G} \backslash\left\{g_{7}\right\}} F(g)$, Part (ii) of the definition is clearly satisfied. Moreover, Part (i) is satisfied, since any deviation from $g_{7}$ may lead back to $g_{7}$. Clearly, $\left\{g_{7}\right\}$ is minimal, so Part (iii) is satisfied too.

There are no other pairwise farsightedly stable sets. Since $F\left(g_{7}\right)=\emptyset$, Part (ii) implies that $g_{7}$ belongs to any pairwise farsightedly stable set. Since $\left\{g_{7}\right\}$ is pairwise farsightedly stable, using Part (iii) it follows that $\left\{g_{7}\right\}$ is the only pairwise farsightedly stable set.

We now consider the case $\phi \geq 3 / 2$. We have $F\left(g_{0}\right)=\left\{g_{1}, g_{2}, g_{3}, g_{4}, g_{5}, g_{6}, g_{7}\right\}, F\left(g_{1}\right)=$ $\left\{g_{4}, g_{5}, g_{7}\right\}, F\left(g_{2}\right)=\left\{g_{4}, g_{6}, g_{7}\right\}, F\left(g_{3}\right)=\left\{g_{5}, g_{6}, g_{7}\right\}, F\left(g_{4}\right)=\left\{g_{7}\right\}, F\left(g_{5}\right)=\left\{g_{7}\right\}$, $F\left(g_{6}\right)=\left\{g_{7}\right\}$, and $F\left(g_{7}\right)=\emptyset$. So, $g_{7} \in \bigcap_{g \in \mathbb{G} \backslash\left\{g_{7}\right\}} F(g)$. Since $F\left(g_{7}\right)=\emptyset$, we can use the same arguments as in the case $\phi<3 / 2$ and can therefore conclude that $\left\{g_{7}\right\}$ is the unique pairwise farsightedly stable set.

The next theorem provides an easy to verify condition for a set to be pairwise farsightedly stable.

Theorem 2 If for every $g \in \mathbb{G} \backslash G$ we have $F(g) \cap G \neq \emptyset$ and for every $g^{\prime} \in G, F\left(g^{\prime}\right) \cap G=$ $\emptyset$, then $G$ is a pairwise farsightedly stable set.

Proof. Part (ii) is trivially satisfied.

Suppose Part (i) is not satisfied. Then there is $g^{\prime} \in G$ and a deviation to $g \notin G$ such that every $g^{\prime \prime} \in G \cap F(g)$ defeats $g^{\prime}$. In particular, it then follows that $g^{\prime \prime} \in F\left(g^{\prime}\right)$, a 
contradiction, since by assumption there is no $g^{\prime \prime} \in G$ with that property. Consequently, Part (i) holds.

To verify Part (iii), suppose there is a proper subset $G^{\prime}$ of $G$ that satisfies Parts (i) and (ii). Let $g^{\prime}$ be in $G$ but not in $G^{\prime}$. By assumption, $F\left(g^{\prime}\right) \cap G=\emptyset$ for every $g^{\prime} \in G$, so $F\left(g^{\prime}\right) \cap G^{\prime}=\emptyset$, and $G^{\prime}$ violates Part (ii), leading to a contradiction. It follows that $G$ is minimal.

A byproduct of Example 4, to be presented later on in the paper, is that Theorem 2 cannot be extended to an "if and only if" statement. The "if and only if" statement is true, however, when restricting the scope of the theorem to sets consisting of a single network.

Theorem 3 The set $\{g\}$ is a pairwise farsightedly stable set if and only if for every $g^{\prime} \in \mathbb{G} \backslash\{g\}$ we have $g \in F\left(g^{\prime}\right)$.

Proof. If $\{g\}$ is a pairwise farsightedly stable set then by Part (ii) in Definition 3 it follows that $\forall g^{\prime} \in \mathbb{G} \backslash\{g\}$ it holds $g \in F\left(g^{\prime}\right)$.

Now suppose that for every $g^{\prime} \in \mathbb{G} \backslash\{g\}$ we have $g \in F\left(g^{\prime}\right)$. Part (ii) is trivially satisfied. Since $g \in F(g+i j)$ and $g \in F(g-i j)$, Parts (ia) and (ib) hold. Finally, Part (iii) is satisfied because $\{g\}$ is a singleton.

Theorem 3 tells us that $\{g\}$ is a pairwise farsightedly stable set if and only if there exists a farsightedly improving path from any network leading to $g$. Part (iii) of the definition implies that if $\{g\}$ is a pairwise farsightedly stable set, then $g$ does not belong to any other pairwise farsightedly stable set. But there may be pairwise farsightedly stable sets not containing $g$.

The next result provides a full characterization for unique pairwise farsightedly stable sets.

Theorem 4 The set $G$ is the unique pairwise farsightedly stable set if and only if $G=$ $\{g \in \mathbb{G} \mid F(g)=\emptyset\}$ and for every $g \in \mathbb{G} \backslash G, F(g) \cap G \neq \emptyset$.

Proof. $(\Leftarrow)$ Part (ii) of Definition 3 is trivially satisfied. Suppose Part (i) is not satisfied. Then there is $g^{\prime} \in G$ and a deviation to $g \notin G$ such that every $g^{\prime \prime} \in G \cap F(g)$ defeats $g^{\prime}$. In particular, it then follows that $g^{\prime \prime} \in F\left(g^{\prime}\right)$, a contradiction, since by assumption $F\left(g^{\prime}\right)=\emptyset$. Consequently, Part (i) holds. Since $F(g)=\emptyset, \forall g \in G$, by Part ii it holds that $G$ is a subset of any pairwise farsightedly stable set. It then follows from Part (iii) that $G$ is the unique pairwise farsightedly stable set.

$(\Rightarrow)$ Part (ii) yields that $\forall g \in \mathbb{G} \backslash G, F(g) \cap G \neq \emptyset$. It remains to be shown that $F(g)=\emptyset, \forall g \in G$. Suppose not, so let $g^{*}$ and $g^{\prime}$ be such that $g^{*} \in G$ and $g^{\prime} \in F\left(g^{*}\right)$. 
Consider $G^{\prime}=\left\{g^{\prime}\right\} \cup\left\{g \in \mathbb{G} \mid g^{\prime} \notin F(g)\right\}$. Notice that $g^{*} \notin G^{\prime}$ and that for any $g \notin G^{\prime}$ we have that $g^{\prime} \in F(g)$.

Claim: $G^{\prime}$ satisfies Part (i) and (ii).

By construction of $G^{\prime}$, Part (ii) is satisfied. Consider any pairwise deviation from $g^{\prime}$ to $g^{\prime \prime} \notin G^{\prime}$. By construction of $G^{\prime}, g^{\prime} \in F\left(g^{\prime \prime}\right)$ and the deviation is deterred. Consider any pairwise deviation from any $g^{0} \in G^{\prime} \backslash\left\{g^{\prime}\right\}$ to some $g^{\prime \prime} \notin G^{\prime}$. Suppose that all $g \in F\left(g^{\prime \prime}\right) \cap G^{\prime}$ are preferred by the players initially deviating to $g^{0}$, then it follows that $F\left(g^{\prime \prime}\right) \cap G^{\prime} \subseteq F\left(g^{0}\right)$. By definition of $G^{\prime}, g^{\prime} \in F\left(g^{\prime \prime}\right)$, so $g^{\prime} \in F\left(g^{\prime \prime}\right) \cap G^{\prime} \subseteq F\left(g^{0}\right)$, contradicting $g^{\prime} \notin F\left(g^{0}\right)$ for any $g^{0} \in G^{\prime} \backslash\left\{g^{\prime}\right\}$. Consequently, all pairwise deviations from $g^{0} \in G^{\prime} \backslash\left\{g^{\prime}\right\}$ are deterred. Since pairwise deviations from $g^{\prime}$ are deterred too, the set $G^{\prime}$ satisfies Part (ii).

Finally, if $G^{\prime}$ satisfies Part (iii), then $G^{\prime}$ is a pairwise farsightedly stable set, a contradiction to the uniqueness of $G$. If $G^{\prime}$ does not satisfy Part (iii), then, following the reasoning in the proof of Theorem 1, there is a proper subset $G^{\prime \prime}$ of $G^{\prime}$ satisfying (i), (ii) and (iii). Since $g^{*} \in G$, but $g^{*} \notin G^{\prime \prime}$, we obtain a contradiction to the uniqueness of $G$.

From Theorem 4 we obtain the following corollary that provides the necessary and sufficient conditions such that there is a unique pairwise farsightedly stable set consisting of a single network.

Corollary 1 The set $\{g\}$ is the unique pairwise farsightedly stable set if and only if for every $g^{\prime} \in \mathbb{G} \backslash\{g\}$ we have $g \in F\left(g^{\prime}\right)$ and $F(g)=\emptyset$.

When we compare Corollary 1 to Theorem 3, we find that Part (ii) of Definition 3 together with $F(g)=\emptyset$ leads to uniqueness of $\{g\}$ as a pairwise farsightedly stable set, whereas Part (ii) together with a non-empty $F(g)$ leads to the existence of at least two pairwise farsightedly stable sets, one of which is $\{g\}$.

Example 2 Symmetric Connections Model (Jackson and Wolinsky, 1996). Players form links with each other in order to exchange information. If player $i$ is connected to player $j$, by a path of $t$ links, then player $i$ receives a payoff of $\delta^{t}$ from his indirect connection with player $j$. It is assumed that $0<\delta<1$, and so the payoff $\delta^{t}$ decreases as the path connecting players $i$ and $j$ increases; thus information that travels a long distance becomes diluted and is less valuable than information obtained from a closer neighbor. Each direct link $i j$ results in a cost $c$ to both $i$ and $j$. This cost can be interpreted as the time a player must spend with another player in order to maintain a direct link. Player $i$ 's payoff from a network $g$ is given by

$$
Y_{i}(g)=\sum_{j \neq i} \delta^{t(i j)}-\sum_{j: i j \in g} c
$$



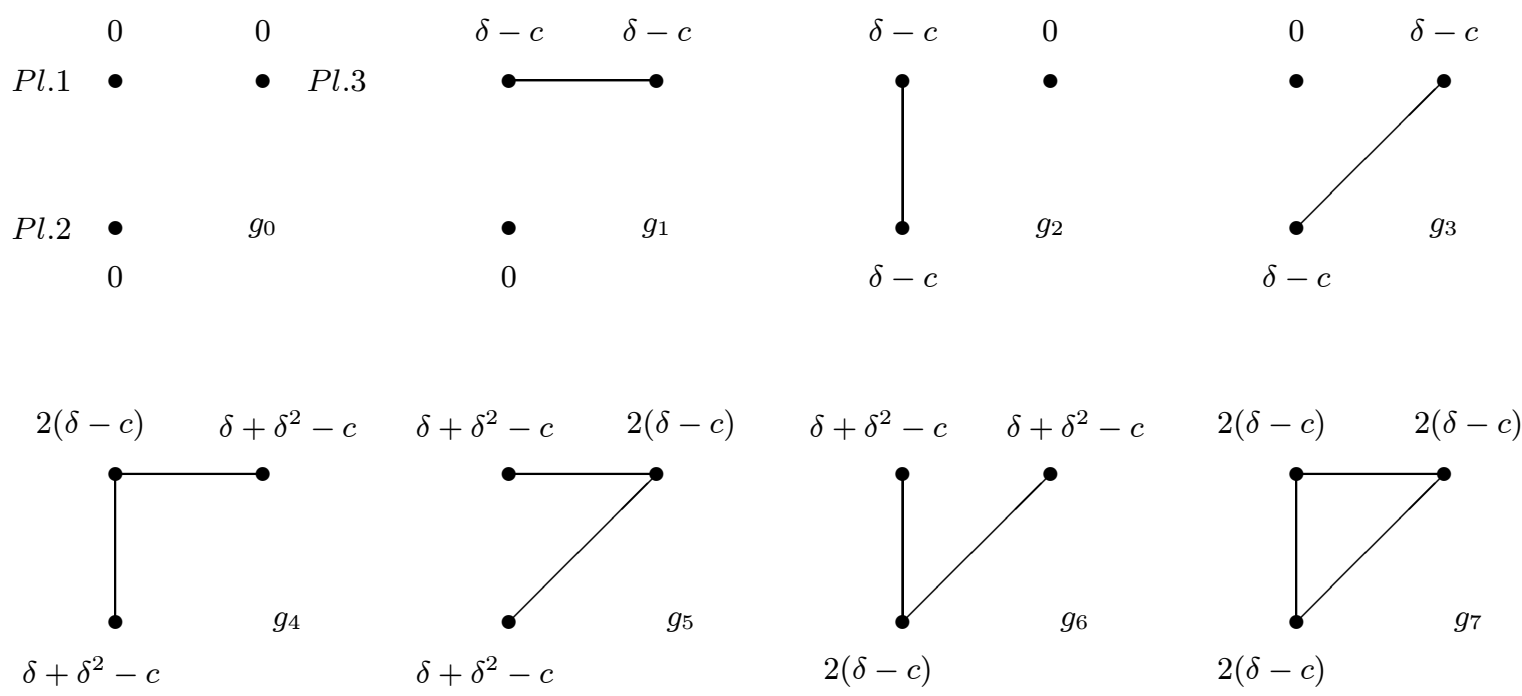

Figure 2: The symmetric connections model with three players.

where $t(i j)$ is the number of links in the shortest path between $i$ and $j$ (setting $t(i j)=\infty$ if there is no path between $i$ and $j$ ).

In Figure 2 we have depicted the 3 -player case where (i) for $c<\delta(1-\delta)$, the complete network ( $g_{7}$ in Figure 2) is the unique pairwise stable network, (ii) for $\delta(1-\delta)<c<\delta$, the star networks $\left(g_{4}, g_{5}, g_{6}\right.$ in Figure 2) are pairwise stable, (iii) for $c>\delta$, the empty network is the unique pairwise stable network.

Applying our newly defined concept of farsightedly stable sets to the symmetric connections model with three players, we obtain that a network $g$ is pairwise stable if and only if $\{g\}$ is pairwise farsightedly stable. First we consider the case $c<\delta(1-\delta)$. It holds that $F\left(g_{0}\right)=\left\{g_{1}, g_{2}, g_{3}, g_{4}, g_{5}, g_{6}, g_{7}\right\}, F\left(g_{1}\right)=\left\{g_{4}, g_{5}, g_{6}, g_{7}\right\}, F\left(g_{2}\right)=\left\{g_{4}, g_{5}, g_{6}, g_{7}\right\}$, $F\left(g_{3}\right)=\left\{g_{4}, g_{5}, g_{6}, g_{7}\right\}, F\left(g_{4}\right)=\left\{g_{5}, g_{6}, g_{7}\right\}, F\left(g_{5}\right)=\left\{g_{4}, g_{6}, g_{7}\right\}, F\left(g_{6}\right)=\left\{g_{4}, g_{5}, g_{7}\right\}$, and $F\left(g_{7}\right)=\emptyset$. Now it follows by Corollary 1 that $\left\{g_{7}\right\}$ is the unique pairwise farsightedly stable set.

Next we consider the case $\delta(1-\delta)<c<\delta$. It holds that $F\left(g_{0}\right)=\left\{g_{1}, g_{2}, g_{3}, g_{4}, g_{5}, g_{6}\right\}$, $F\left(g_{1}\right)=\left\{g_{4}, g_{5}, g_{6}\right\}, F\left(g_{2}\right)=\left\{g_{4}, g_{5}, g_{6}\right\}, F\left(g_{3}\right)=\left\{g_{4}, g_{5}, g_{6}\right\}, F\left(g_{4}\right)=\left\{g_{5}, g_{6}\right\}, F\left(g_{5}\right)=$ $\left\{g_{4}, g_{6}\right\}, F\left(g_{6}\right)=\left\{g_{4}, g_{5}\right\}$, and $F\left(g_{7}\right)=\left\{g_{4}, g_{5}, g_{6}\right\}$.

By a repeated application of Theorem 3, it follows that $\left\{g_{4}\right\},\left\{g_{5}\right\}$, and $\left\{g_{6}\right\}$ are pairwise farsightedly stable.

Finally, we examine the case $c>\delta$. One may verify that $F\left(g_{0}\right)=\emptyset, F\left(g_{1}\right)=$ $\left\{g_{0}\right\}, F\left(g_{2}\right)=\left\{g_{0}\right\}, F\left(g_{3}\right)=\left\{g_{0}\right\}, F\left(g_{4}\right)=\left\{g_{0}, g_{1}, g_{2}\right\}, F\left(g_{5}\right)=\left\{g_{0}, g_{1}, g_{3}\right\}, F\left(g_{6}\right)=$ $\left\{g_{0}, g_{2}, g_{3}\right\}$, and $F\left(g_{7}\right)=\left\{g_{0}, g_{1}, g_{2}, g_{3}, g_{4}, g_{5}, g_{6}\right\}$. It follows by Corollary 1 that $\left\{g_{0}\right\}$ is the unique pairwise farsightedly stable set. 
Thus, Examples 1 and 2 suggest that pairwise farsighted stability may be a refinement of pairwise stability as defined by Jackson and Wolinsky (1996). However, the next example shows that the pairwise stable networks may not belong to any pairwise farsightedly stable set of networks.

Example 3 Suppose that four players can form links. In the empty network, $Y_{i}(g)=0$ for all $i \in N$. In any $g$ such that $\#(g)=1$ and player 4 does not belong to $N(g)$, we have $Y_{4}(g)=1$. Moreover, $Y_{1}(\{12\})=Y_{3}(\{13\})=Y_{2}(\{23\})=4, Y_{2}(\{12\})=Y_{1}(\{13\})=$ $Y_{3}(\{23\})=2, Y_{1}(\{23\})=Y_{2}(\{13\})=Y_{3}(\{12\})=1$. In any $g$ such that $\#(g)=2$ and player 4 does not belong to $N(g)$, we have $Y_{i}(g)=3$ for $i \in N(g)$, and $Y_{4}(g)=1$. We define $Y_{i}(\{12,13,23\})=-1$ for all $i \in N$. Finally, in any other network $g$, let $Y_{i}(g)=0$ for all $i \in N$. Figure 3 presents most of these network configurations. In this example the pairwise stable networks are the complete network as well as the networks such that \# $(g)$ equals 4 or 5 .

We have $F\left(g_{1}\right)=\left\{g_{2}, g_{3}, g_{4}, g_{5}, g_{6}\right\}, F\left(g_{2}\right)=\left\{g_{1}, g_{3}, g_{4}, g_{5}, g_{6}\right\}, F\left(g_{3}\right)=\left\{g_{1}, g_{2}, g_{4}, g_{5}, g_{6}\right\}$, $F\left(g_{4}\right)=F\left(g_{5}\right)=F\left(g_{6}\right)=\left\{g_{1}, g_{2}, g_{3}\right\}, F\left(g_{7}\right)=\left\{g_{1}, g_{2}, g_{3}, g_{4}, g_{5}, g_{6}\right\} \cup\left\{g_{7}+i j \mid i j \notin g_{7}\right\}$, and $F(g)=\left\{g_{1}, g_{2}, g_{3}, g_{4}, g_{5}, g_{6}\right\}$ for any other $g$. The pairwise farsightedly stable sets are $\left\{g_{1}\right\},\left\{g_{2}\right\},\left\{g_{3}\right\}$, and $\left\{g_{4}, g_{5}, g_{6}\right\}$. On the contrary, the pairwise stable networks are all networks $g$ with $\#(g) \geq 4$.

Pairwise farsighted stability is a refinement of pairwise stability when there is a unique pairwise farsightedly stable set.

Theorem 5 If $G$ is the unique pairwise farsightedly stable set and the network $g$ belongs to $G$, then $g$ is pairwise stable.

Proof. By Theorem 4, for $g \in G, F(g)=\emptyset$, which implies that $g$ is pairwise stable.

Corollary 2 If $\{g\}$ is the unique pairwise farsightedly stable set, then $g$ is pairwise stable.

\section{Efficiency and farsighted stability}

We now turn to the question of the relationship between farsighted stability and efficiency of networks. A first result is that the set of pairwise farsightedly stable networks and the set of strongly efficient networks, those which are socially optimal, may be disjoint for all 

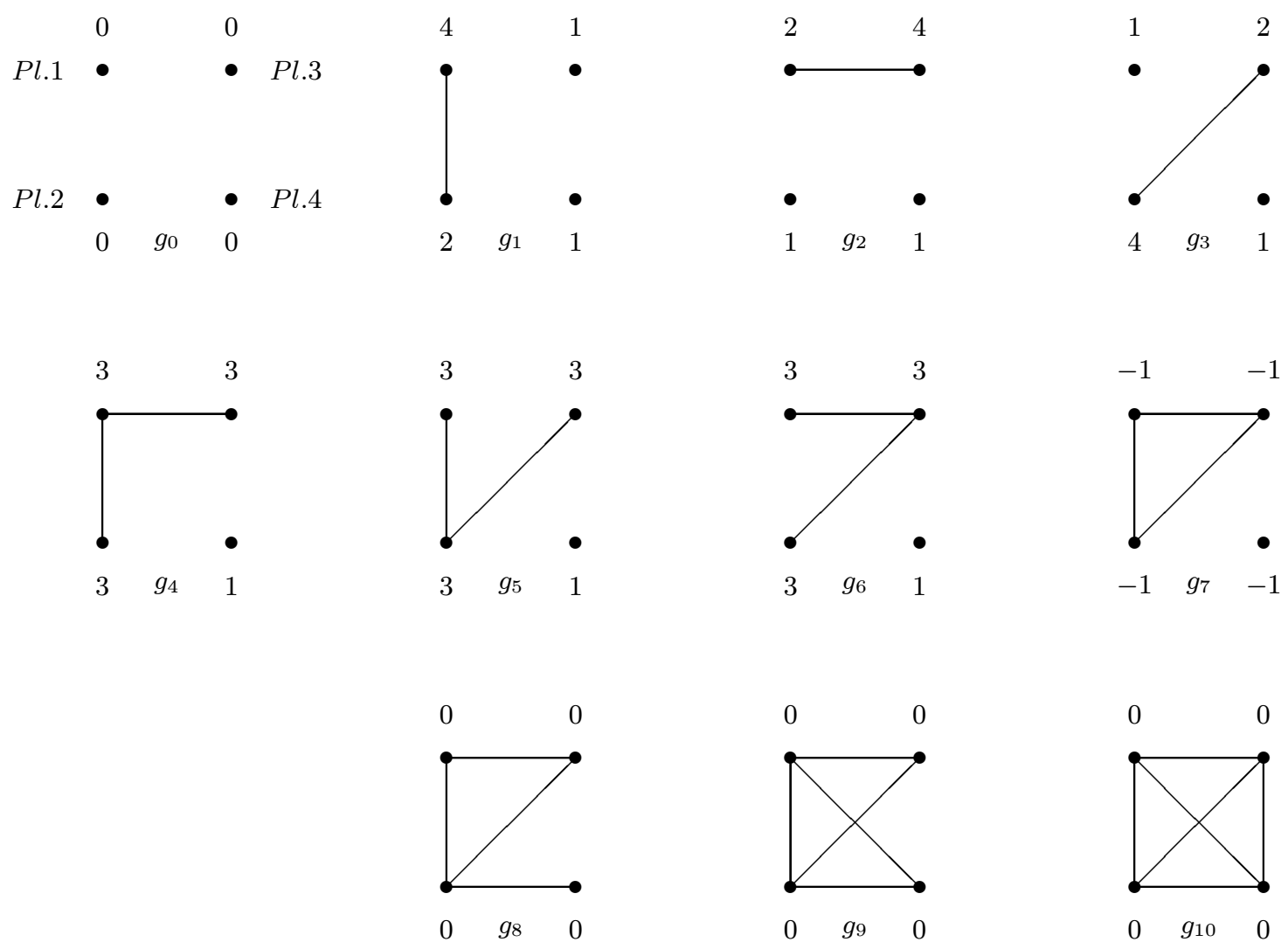

Figure 3: Pairwise farsighted stability and pairwise stability.

allocation rules that are component balanced and anonymous. ${ }^{13}$

Theorem 6 There exists a value function such that for every component balanced and anonymous rule, strongly efficient networks are not included in any of the pairwise farsightedly stable sets.

Proof. Take the following value function defined for any $g \in \mathbb{G}: v(\{12,13,23\})=9$, $v(\{12,23\})=0, v(\{12,13\})=0, v(\{13,23\})=0, v(\{12\})=8, v(\{23\})=8, v(\{13\})=8$, and $v(\emptyset)=0$. Fix any component balanced and anonymous allocation rule $Y$. Then, by component balance and anonymity,

(i) $Y_{1}(\{12,13,23\}, v)=Y_{2}(\{12,13,23\}, v)=Y_{3}(\{12,13,23\}, v)=3$,

\footnotetext{
${ }^{13}$ Bhattacharya (2005) has obtained a similar result with respect to the notion of the largest consistent set.
} 
(ii) $Y_{1}(\{12,23\}, v)=c, Y_{3}(\{12,23\}, v)=c, Y_{2}(\{12,23\}, v)=-2 c, Y_{2}(\{12,13\}, v)=c$, $Y_{3}(\{12,13\}, v)=c, Y_{1}(\{12,13\}, v)=-2 c, Y_{1}(\{13,23\}, v)=c, Y_{2}(\{13,23\}, v)=c$, $Y_{3}(\{13,23\}, v)=-2 c$,

(iii) $Y_{1}(\{12\}, v)=Y_{2}(\{12\}, v)=4, Y_{3}(\{12\}, v)=0, Y_{1}(\{13\}, v)=Y_{3}(\{13\}, v)=4$, $Y_{2}(\{13\}, v)=0, Y_{2}(\{23\}, v)=Y_{3}(\{23\}, v)=4, Y_{1}(\{23\}, v)=0$, and

(iv) $Y_{1}(\emptyset, v)=Y_{2}(\emptyset, v)=Y_{3}(\emptyset, v)=0$.

The unique strongly efficient network is $\{12,13,23\}$. We have:

(i) $F(\emptyset)=\{\{12\},\{13\},\{23\},\{12,13,23\}\}$;

(ii) $F(\{12\})=\{\{13\},\{23\}\}, F(\{13\})=\{\{12\},\{23\}\}, F(\{23\})=\{\{12\},\{13\}\}$;

(iii) For $c<3, F(\{12,13\})=\{\{12\},\{13\},\{23\},\{12,13,23\}\}$, for $3 \leq c<4, F(\{12,13\})=$ $\{\{12\},\{13\},\{23\}\}$, and for $c \geq 4, F(\{12,13\})=\{\{12\},\{13\}\}$. Next, for $c<3$, $F(\{12,23\})=\{\{12\},\{13\},\{23\},\{12,13,23\}\}$, for $3 \leq c<4, F(\{12,23\})=\{\{12\}$, $\{13\},\{23\}\}$, and for $c \geq 4, F(\{12,23\})=\{\{12\},\{23\}\}$. And, for $c<3, F(\{13,23\})=$ $\{\{12\},\{13\},\{23\},\{12,13,23\}\}$, for $3 \leq c<4, F(\{13,23\})=\{\{12\},\{13\},\{23\}\}$, and for $c \geq 4, F(\{13,23\})=\{\{13\},\{23\}\}$;

(iv) For $c<3, F(\{12,13,23\})=\{\{12\},\{13\},\{23\},\{12,13\},\{12,23\},\{13,23\}\}$, for $c \geq 3$, $F(\{12,13,23\})=\{\{12\},\{13\},\{23\}\}$.

Thus, $\{\{12\}\},\{\{13\}\}$, and $\{\{23\}\}$ are the only pairwise farsightedly stable sets.

A second result considers the case where there is a network that strictly Pareto dominates all other networks. That is, if there is a network $g$ such that for all $g^{\prime} \in \mathbb{G} \backslash\{g\}$ it holds that, for all $i, Y_{i}(g, v)>Y_{i}\left(g^{\prime}, v\right)$. Although the network that strictly Pareto dominates all others is pairwise stable, there might be many more pairwise stable networks. We will show in Section 5 that also the concept of the pairwise largest consistent set suffers from a similar defect. The following result asserts that pairwise farsighted stability singles out the Pareto dominating network as the unique pairwise farsightedly stable set.

Theorem 7 If there is a network $g$ that strictly Pareto dominates all other networks, then $\{g\}$ is the unique pairwise farsightedly stable set.

Proof. It is immediate that $g \in F\left(g^{\prime}\right)$ for all $g^{\prime} \in \mathbb{G} \backslash\{g\}$ and that $F(g)=\emptyset$. Corollary 1 leads to the desired result. 
We next provide sufficient conditions on the allocation rule and/or the value function such that there is no conflict between strong efficiency and farsighted stability.

An immediate application of Theorem 7 is the case of increasing returns to link creation as defined in Dutta, Ghosal, and Ray (2005). This property requests that along every nested sequence of increasingly connected networks, there is a threshold network for which the value turns nonnegative, and both aggregate as well as payoffs of individuals who form extra links then increase as the network becomes even larger. Under this condition, and with a componentwise egalitarian allocation rule, $g^{N}$ Pareto dominates all other networks, so Theorem 7 applies.

An allocation rule is said to be egalitarian if for every $v \in \mathcal{V}$ and $g \in \mathbb{G}, Y_{i}(g, v)=$ $v(g) / n$. The following result follows as a corollary to Theorem 7 .

Corollary 3 Suppose that $Y$ is the egalitarian rule and there is a unique strongly efficient network $g^{e}$. Then, $\left\{g^{e}\right\}$ is the unique pairwise farsightedly stable set.

Before studying the relationship between pairwise farsightedly stable sets and other farsighted solution concepts we analyze some classical examples.

Example 4 Co-author Model (Jackson and Wolinsky, 1996). Each player is a researcher who spends time writing papers. If two players are connected, then they are working on a paper together. The amount of time researcher $i$ spends on a given project is inversely related to the number of projects, $n_{i}$, that he is involved in. Formally, player $i$ 's payoff is given by

$$
Y_{i}(g)=\sum_{j: i j \in g}\left(\frac{1}{n_{i}}+\frac{1}{n_{j}}+\frac{1}{n_{i} n_{j}}\right)
$$

for $n_{i}>0$. For $n_{i}=0$ we assume that $Y_{i}(g)=0$. In Figure 4 we have depicted the 3 -player case. It is easily verified that the complete network $g_{7}$ is the unique pairwise stable network.

Unfortunately, no singleton set is pairwise farsightedly stable in Example 4. Indeed, there is no network such that there is a farsightedly improving path from any other network leading to it. More precisely, $F\left(g_{0}\right)=\left\{g_{1}, g_{2}, g_{3}, g_{4}, g_{5}, g_{6}\right\}, F\left(g_{1}\right)=\left\{g_{4}, g_{5}\right\}$, $F\left(g_{2}\right)=\left\{g_{4}, g_{6}\right\}, F\left(g_{3}\right)=\left\{g_{5}, g_{6}\right\}, F\left(g_{4}\right)=\left\{g_{7}\right\}, F\left(g_{5}\right)=\left\{g_{7}\right\}, F\left(g_{6}\right)=\left\{g_{7}\right\}$, and $F\left(g_{7}\right)=\emptyset$. However, a set formed by the complete and two star networks is a pairwise farsightedly stable set of networks. The pairwise farsightedly stable sets are $\left\{g_{4}, g_{5}, g_{7}\right\}$, $\left\{g_{4}, g_{6}, g_{7}\right\}$, and $\left\{g_{5}, g_{6}, g_{7}\right\}$ in the co-author model with three players. 


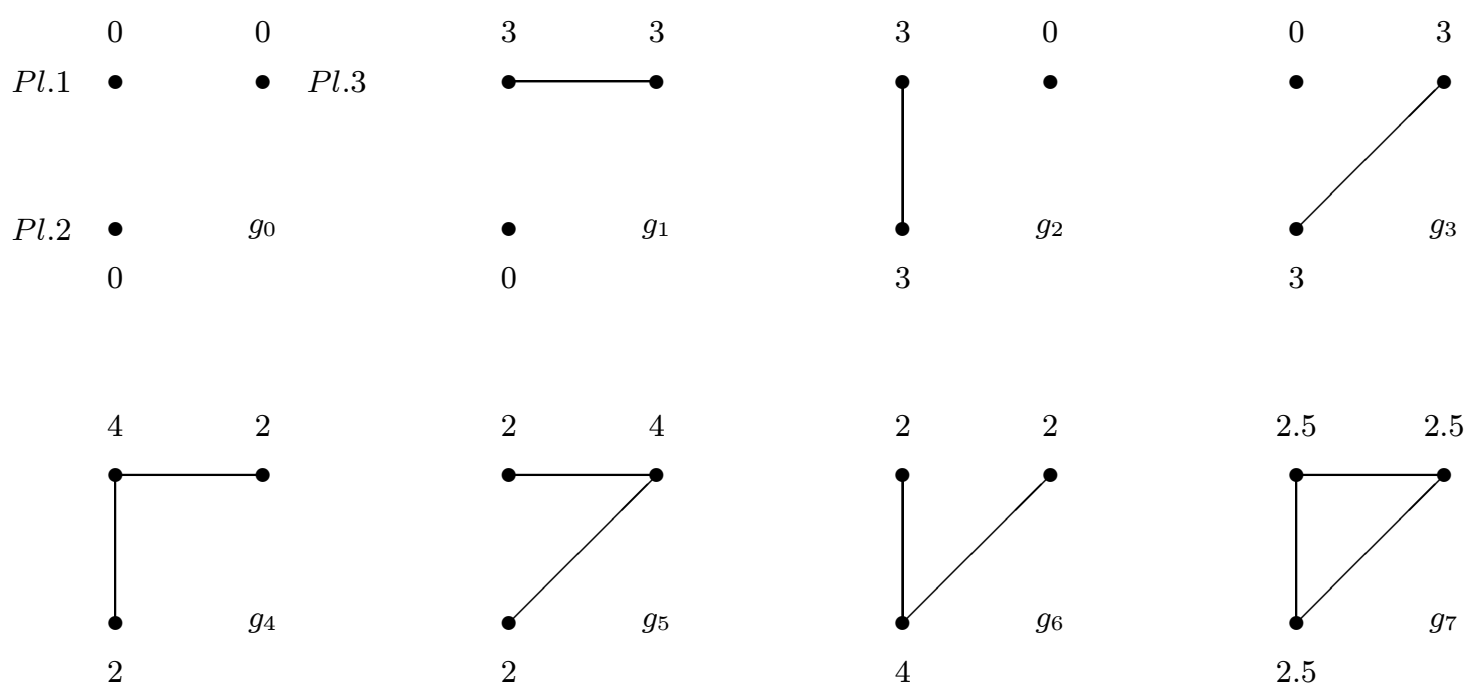

Figure 4: The co-author model with three players.

Example 5 Symmetric Connections Model (Jackson and Wolinsky, 1996). Consider again the symmetric connections model of Example 2 but now with four players, see Figure 5. In Figure 5 all possible networks, up to permutations of players, are depicted. For instance, the circle network, $g_{8}$, represents the four possible circle networks. As before, we assume $0<\delta<1$.

First consider the case $c<\delta(1-\delta)$. In this case, irrespective of the network, making a link always strictly improves the payoffs of the players involved in making the link. From this observation it follows immediately that the complete network $g_{10}$ is the unique pairwise stable network. Moreover, from any initial network except the complete one, it is possible to reach the complete network by a farsightedly improving path. There are no other networks that are reached by a farsightedly improving path when starting in the complete network. It follows from Corollary 1 that the complete network is the unique pairwise farsightedly stable set.

Next, suppose that $\delta(1-\delta)<c<\delta\left(1-\delta^{2}\right)$. Observe that $2(\delta-c)+\delta^{2}$ strictly exceeds $3(\delta-c)$ and $\delta+\delta^{2}+\delta^{3}-c$, but is lower than $\delta+2 \delta^{2}-c$. From this observation it follows easily that a network is pairwise stable if and only if it is one of the four stars or the four circle networks $\left(g_{6}, g_{8}\right.$ in Figure 5$)$.

Moreover, $\left\{g_{6}\right\}$ and $\left\{g_{8}^{1}, g_{8}^{2}, g_{8}^{3}, g_{8}^{4}\right\}$ are pairwise farsightedly stable sets, where $\left\{g_{8}^{1}, g_{8}^{2}, g_{8}^{3}\right.$, $\left.g_{8}^{4}\right\}$ denotes the set of all circle networks. For any star this follows from the observation that $g_{6}$ leads to the highest possible payoff $\delta+2 \delta^{2}-c$ for three out of four players. For all networks but $g_{7}$ it holds that none of the players gets this payoff, so there are at least three players that would be willing to move to $g_{6}$. They can do so by first destroying all 

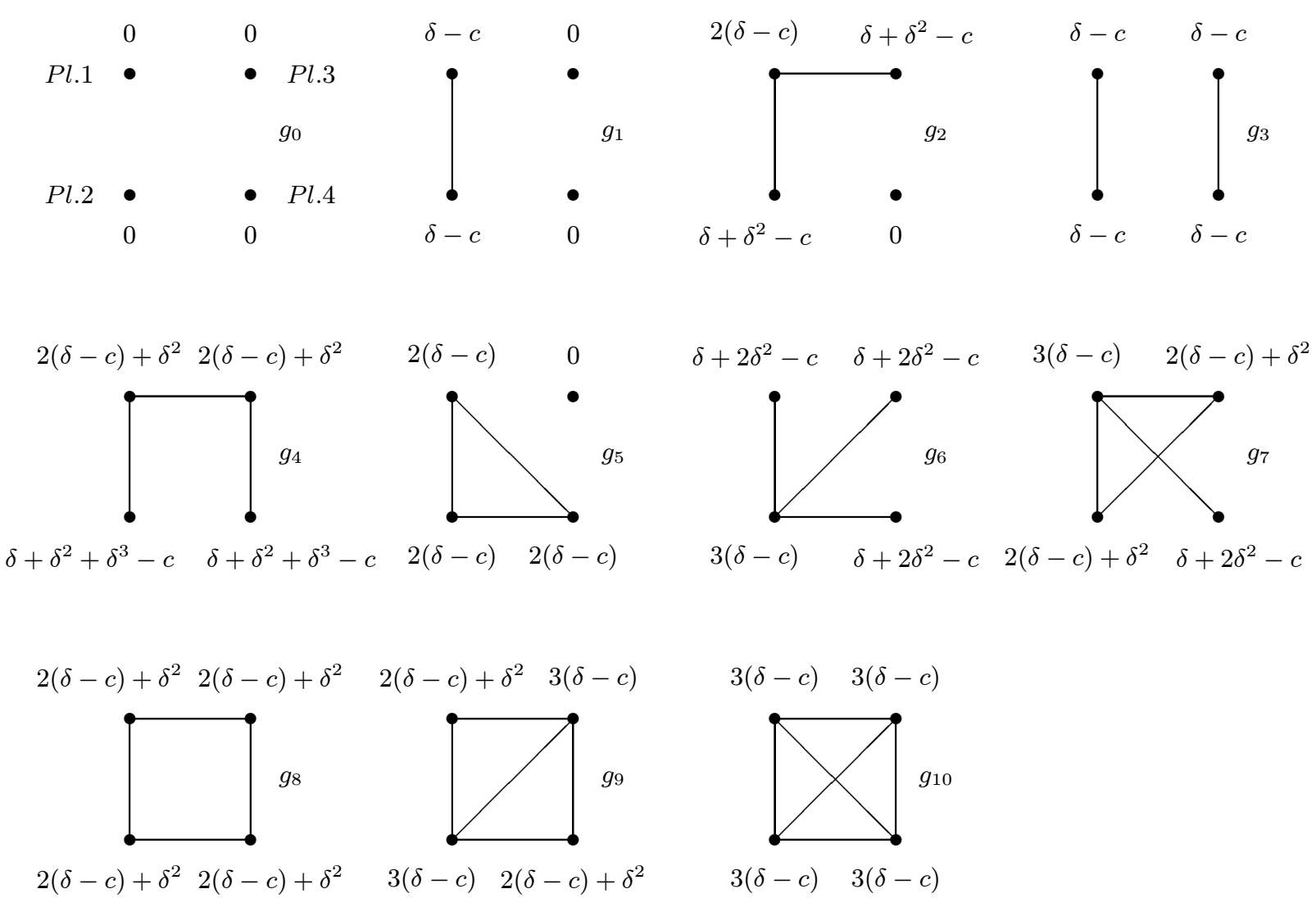

Figure 5: The symmetric connections model with four players.

links in an appropriate order, and next adding links to reach the specific star $g_{6}$ they coordinate on. Links have to be destroyed in such a way that on the sequence of networks thus obtained, no player gets payoff $\delta+2 \delta^{2}-c$. Also, any star $g_{6}$ can be reached by a farsightedly improving path starting in any of the four possible networks $g_{7}$. Take a specific star $g_{6}$ and a specific network $g_{7}$. If the player with payoff $\delta+2 \delta^{2}-c$ at $g_{7}$ obtains less at $g_{6}$, then the other three players would strictly improve by going to $g_{6}$. They can do so by destroying all links, and then add links to reach the desired star $g_{6}$. If the player with payoff $\delta+2 \delta^{2}-c$ at $g_{7}$ obtains the same payoff at $g_{6}$, then there are two players that are strictly better off at $g_{6}$. Together they can destroy at least two links of $g_{7}$, in which case a network with only one link remains, and all players would be willing to move from there to $g_{6}$. Finally, it is possible to reach any star from another, different, star, by means of a farsightedly improving path. The player with three links is willing to destroy all of them and move to $g^{0}$, from which any star can be reached by adding the appropriate three links. It therefore follows from Theorem 3 that $\left\{g_{6}\right\}$ is pairwise farsightedly stable. 
It is fairly straightforward that any circle $g_{8}$ belongs to $F(g)$ whenever $g$ is not equal to $g_{6}$ or $g_{7}$. For $g_{6}$ notice that the player with payoff $3(\delta-c)$ may first delete all links to go to $g_{0}$, after which three links are added and any $g_{8}$ is reached via $g_{1}, g_{2}$, and $g_{4}$. For $g_{7}$ the player with payoff $3(\delta-c)$ can sever three links to go to $g_{1}$, after which one more link is deleted by any of the players involved in the remaining link, to go to $g_{0}$. Next links are added to reach $g_{8}$ in the same way as before. Since all the circles lead to identical payoffs, it is not possible to reach a circle from a different circle by means of a farsightedly improving path. It follows from Definition 3 that $\left\{g_{8}^{1}, g_{8}^{2}, g_{8}^{3}, g_{8}^{4}\right\}$ is pairwise farsightedly stable.

The next case is $\delta\left(1-\delta^{2}\right)<c<\delta$. For this case it is crucial that $3(\delta-c)<2(\delta-c)+\delta^{2}<$ $\delta+\delta^{2}+\delta^{3}-c<\delta+2 \delta^{2}-c$. It is straightforward to verify that any of the six pairs of chains $\left\{g_{4}^{1234}, g_{4}^{1324}\right\},\left\{g_{4}^{1243}, g_{4}^{1423}\right\},\left\{g_{4}^{1342}, g_{4}^{1432}\right\},\left\{g_{4}^{2134}, g_{4}^{2314}\right\},\left\{g_{4}^{2143}, g_{4}^{2413}\right\},\left\{g_{4}^{3124}, g_{4}^{3214}\right\}$, and any of the four stars ( $g_{6}$ in Figure 5 ) is pairwise stable. Here, the notation for the chains refers to the links that are present. For instance, $g_{4}^{1234}$ denotes the chain with links $\{1,2\}$, $\{2,3\}$, and $\{3,4\}$. Notice that the payoffs are the same for all players for any two chains in any of the six pairs.

That any star $\left\{g_{6}\right\}$ is pairwise farsightedly stable follows from exactly the same argument as in the case $\delta(1-\delta)<c<\delta\left(1-\delta^{2}\right)$. Now consider a specific chain $g_{4}$. For all networks, but $g_{4}, g_{6}$, and $g_{7}$, the two players in $g_{4}$ with payoffs $\delta+\delta^{2}+\delta^{3}-c$ are willing to destroy their links to arrive at $g_{1}$. Then the remaining link at $g_{1}$ is severed too and $g_{0}$ is reached. From there, players can add links to go to $g_{4}$. Next consider a specific star $g_{6}$ as the starting network. The player with payoff $3(\delta-c)$ is sure to receive higher payoffs in $g_{4}$. He is willing to destroy all links, and $g_{4}$ is reached via $g_{0}$. For $g_{7}$ the construction is similar, and $g_{4}$ can be reached via $g_{1}$ and $g_{0}$. Consider two chains that do no belong to the same pair. There is at least one player that receives payoff $2(\delta-c)+\delta^{2}$ in one chain, but not in the other. This player is willing to delete a link to go to either $g_{2}$ or $g_{3}$. From there it is possible to reach the other chain via $g_{0}$. Obviously, it is not possible to reach the other chain in a pair. It follows from Definition 3 that any pair of chains identified before is pairwise farsightedly stable.

The next case we consider is $\delta+\frac{1}{2} \delta^{2}<c$. We observe that any payoff that is a positive multiple of $\delta-c$ is negative (and the higher the multiple, the more negative). Moreover, the payoff $2(\delta-c)+\delta^{2}$ is negative. Finally, $\delta+\delta^{2}+\delta^{3}-c>\delta+\delta^{2}-c>2(\delta-c)+\delta^{2}>2(\delta-c)$. Next it is easy to verify that in each network but the empty network there is always at least one player that strictly benefits from deleting a link. It follows that the empty network is the only potential pairwise stable network. Since forming a link leads to negative utilities for the players making the link, it follows that the empty network is the unique pairwise 
stable network.

Now we turn to pairwise farsighted stability. It is easily verified that for each network, but $g_{0}$, the set of players with negative payoffs are able to delete all links. It follows that $g_{0} \in F(g)$ for all $g \in \mathbb{G} \backslash\left\{g_{0}\right\}$. Now consider $g_{0}$ as the starting network. For all other networks, there is at least one player with a link that has a negative payoff. Such a player will never cooperate to make the network under consideration the terminal network, and as a consequence $F\left(g_{0}\right)=\emptyset$. We derive from Corollary 1 that $\left\{g_{0}\right\}$ is the unique pairwise farsightedly stable set.

The final case we have to consider is $\delta<c<\delta+\frac{1}{2} \delta^{2}$. As in the previous case, it holds that any payoff that is a positive multiple of $\delta-c$ is negative, and the higher the multiple, the more negative. Moreover, it holds that $0<2(\delta-c)+\delta^{2}<\delta+\delta^{2}-c<\delta+\delta^{2}+\delta^{3}-c$. It is easy to verify that $g_{0}$ is the unique pairwise stable network. However, a pairwise farsightedly stable set that is singleton fails to exist. Indeed, there is no network such that there is a farsightedly improving path from any other network leading to it. The empty network $\left\{g_{0}\right\}$ is not a pairwise farsightedly stable set because obviously $g_{0} \notin F\left(g_{4}\right)$ and $g_{0} \notin F\left(g_{8}\right)$. On the contrary, using by now familiar arguments, it can be shown that any of the six pairs of chains $\left\{g_{4}^{1234}, g_{4}^{1324}\right\},\left\{g_{4}^{1243}, g_{4}^{1423}\right\},\left\{g_{4}^{1342}, g_{4}^{1432}\right\},\left\{g_{4}^{2134}, g_{4}^{2314}\right\}$, $\left\{g_{4}^{2143}, g_{4}^{2413}\right\},\left\{g_{4}^{3124}, g_{4}^{3214}\right\}$ is pairwise farsightedly stable.

\section{The pairwise largest consistent set}

In this section we study the relationship between pairwise farsighted stability and the largest consistent set, a concept that has been defined in Chwe (1994) for general social environments. By considering a network as a social environment, and by allowing only pairwise deviations, we obtain the definition of the pairwise largest consistent set.

Definition 4 Let $Z^{0} \equiv \mathbb{G}$. Then, $Z^{k}(k=1,2, \ldots)$ is inductively defined as follows: $g \in Z^{k-1}$ belongs to $Z^{k}$ with respect to $Y$ and $v$ if

(ia) $\forall i j \notin g, \exists g^{\prime} \in Z^{k-1}$, where $g^{\prime}=g+i j$ or $g^{\prime} \in F(g+i j)$ such that $Y_{i}\left(g^{\prime}, v\right)<Y_{i}(g, v)$ or $Y_{j}\left(g^{\prime}, v\right)<Y_{j}(g, v)$ or $\left(Y_{i}\left(g^{\prime}, v\right), Y_{j}\left(g^{\prime}, v\right)\right)=\left(Y_{i}(g, v), Y_{j}(g, v)\right)$.

(ib) $\forall i j \in g, \exists g^{\prime}, g^{\prime \prime} \in Z^{k-1}$, where $g^{\prime}=g-i j$ or $g^{\prime} \in F(g-i j)$, and $g^{\prime \prime}=g-i j$ or $g^{\prime \prime} \in F(g-i j)$, such that $Y_{i}\left(g^{\prime}, v\right) \leq Y_{i}(g, v)$ and $Y_{j}\left(g^{\prime \prime}, v\right) \leq Y_{j}(g, v)$.

The pairwise largest consistent set $\operatorname{PLCS}(\mathbb{G})$ is $\bigcap_{k \geq 1} Z^{k}$. 
That is, a network $g \in Z^{k-1}$ is stable (at step $k$ ) and belongs to $Z^{k}$, if all possible pairwise deviations are deterred. Consider a pairwise deviation from $g$ that involves making the link $i j$. There might be further pairwise deviations which end up at $g^{\prime}$, where $g+i j \rightarrow g^{\prime}$. If either $i$ or $j$ is worse off at $g^{\prime}$ or both are equally well off compared to the original network $g$ then the pairwise deviation is deterred. Similarly, for a pairwise deviation from $g$ that involves deleting the link $i j$. There might be further pairwise deviations which end up at $g^{\prime}$ and $g^{\prime \prime}$ where $g-i j \rightarrow g^{\prime}$ and $g-i j \rightarrow g^{\prime \prime}$. If $i$ is equally well or worse off at $g^{\prime}$ and $j$ is equally well or worse off at $g^{\prime \prime}$ compared to the original network $g$, then the pairwise deviation is deterred.

Since $\mathbb{G}$ is finite, there exists $m \in \mathbb{N}$ such that $Z^{k}=Z^{k+1}$ for all $k \geq m$, and $Z^{m}$ is the pairwise largest consistent set $P L C S(\mathbb{G})$. Notice that although the pairwise largest consistent set always exists, it could be empty. However, it has been shown in Chwe (1994) that for the case of a finite $\mathbb{G}$ non-emptiness holds.

Example 4 (continued) We determine the pairwise largest consistent set in the co-author model for $n=3$. Starting in $g_{0}$, players $\{1,2\}$ can add a link to move to $g_{1}$. The indirect dominance relation implies that from there it is possible to reach $g_{4}$ or $g_{5}$. In all these networks, players 1 and 2 have higher payoffs than at $g_{0}$. It follows that $g_{0} \notin Z^{1}$. Starting in $g_{4}$, players 2 and 3 will add a link to move to $g_{7}$. Since $F\left(g_{7}\right)=\emptyset$, no further moves will occur. Players 2 and 3 have higher payoffs at $g_{7}$ than at $g_{4}$. It follows that $g_{4} \notin Z^{1}$. For similar reasons, $g_{5} \notin Z^{1}$ and $g_{6} \notin Z^{1}$. It can be verified that $Z^{1}=\left\{g_{1}, g_{2}, g_{3}, g_{7}\right\}$.

We show next that $Z^{2}=\left\{g_{1}, g_{2}, g_{3}, g_{7}\right\}$. Starting in $g_{1}$, players 1 and 2 may add a link to go to $g_{4}$, a network not in $Z^{1}$. From $g_{4}$ the indirect dominance relation dictates a move to $g_{7}$. In $g_{7}$ player 1 is worse off than in $g_{1}$. It follows that no link will be added by them to $g_{1}$. Repeating such arguments, it can be shown that $Z^{2}=\left\{g_{1}, g_{2}, g_{3}, g_{7}\right\}=Z^{3}=\cdots=Z^{\infty}$. It follows that $\operatorname{PLCS}(\mathbb{G})=\left\{g_{1}, g_{2}, g_{3}, g_{7}\right\}$.

Example 3 (continued) We determine the pairwise largest consistent set in the four-player link formation game. One can easily show that $Z^{1}=\left\{g_{1}, g_{2}, g_{3}, g_{4}, g_{5}, g_{6}\right\} \cup\{g \mid \#(g) \geq$ $4\}=Z^{2}=Z^{3}=\cdots=Z^{\infty}$.

Table 1 summarizes our findings in these two examples.

If a network is not in the pairwise largest consistent set, it cannot be a pairwise farsightedly stable set of networks.

Theorem 8 If $\{g\}$ is a pairwise farsightedly stable set, then $g$ belongs to the pairwise largest consistent set PLCS $(\mathbb{G})$. 


\begin{tabular}{|c|cc|}
\hline Concept & Example 3 & Example 4 \\
\hline Pairwise stability & $\{g \mid \#(g) \geq 4\}$ & $\left\{g_{7}\right\}$ \\
\hline Pairwise farsightedly & $\left\{g_{1}\right\},\left\{g_{2}\right\},\left\{g_{3}\right\}$ & $\left\{g_{4}, g_{5}, g_{7}\right\},\left\{g_{4}, g_{6}, g_{7}\right\}$, \\
stable sets of networks & $\left\{g_{4}, g_{5}, g_{6}\right\}$ & $\left\{g_{5}, g_{6}, g_{7}\right\}$ \\
\hline PLCS & $\left\{g_{1}, \ldots, g_{6}\right\}$ & $\left\{g_{1}, g_{2}, g_{3}, g_{7}\right\}$ \\
& $\cup\{g \mid \#(g) \geq 4\}$ & \\
\hline
\end{tabular}

Table 1: The (no)-relationships among solution concepts for network stability.

Proof. Since $\{g\}$ is a pairwise farsightedly stable set we have that for all $i j \notin g: g \in$ $F(g+i j)$ and for all $i j \in g: g \in F(g-i j)$. So $g \in Z^{1}$. By induction, $g \in Z^{k}$ for $k \geq 1$. So, $g \in P L C S(\mathbb{G})$.

Remember that two networks $g$ and $g^{\prime}$ are adjacent if they differ by one link. The value function $v$ and allocation rule $Y$ exhibit no indifference if for any $g$ and $g^{\prime}$ that are adjacent either $g$ defeats $g^{\prime}$ or $g^{\prime}$ defeats $g$.

Theorem 9 Suppose that $Y$ and $v$ exhibit no indifference. If $g$ is pairwise stable then it belongs to the pairwise largest consistent set.

Proof. Since $Y$ and $v$ exhibit no indifference, we have that a pairwise stable network $g$ defeats (i) $g+i j$ for all $i j \notin g$ and (ii) $g-i j$ for all $i j \in g$. Thus, $g \in F(g+i j)$ and $g \in F(g-i j)$. So $g \in Z^{1}$. By induction $g \in Z^{k}$ for $k \geq 1$. So, $g \in P L C S(\mathbb{G})$.

We claimed in Section 4 that even if there is a network that strictly Pareto dominates all other networks, the pairwise largest consistent set may contain other networks. It is not difficult to construct examples where the no indifference property holds, and some network strictly Pareto dominates all others. Moreover, such an example can be constructed such that inefficient networks may be pairwise stable. It then follows from Theorem 9 that such a network also belongs the pairwise largest consistent set. By virtue of Theorem 7, such a network does not belong to any pairwise farsightedly stable set.

\section{Conclusion}

We have proposed a new concept, the pairwise farsightedly stable set, to predict which networks may be formed among farsighted players. A set of networks $G$ is pairwise farsightedly stable (i) if all possible pairwise deviations from any network $g \in G$ to a network outside $G$ are deterred by the threat of ending worse off or equally well off, (ii) if there 
exists a farsightedly improving path from any network outside the set leading to some network in the set, and (iii) if there is no proper subset of $G$ satisfying (i) and (ii). We have shown that a pairwise farsightedly stable set always exists and we provide a full characterization of unique pairwise farsightedly stable sets of networks. As a corollary we have given the necessary and sufficient condition such that a unique pairwise farsightedly stable set consisting of a single network exists. We have found that the pairwise farsightedly stable sets and the set of strongly efficient networks may be disjoint. Nevertheless, contrary to other pairwise concepts, if there is a network that Pareto dominates all other networks, then that network is the unique prediction of pairwise farsighted stability. We have also been able to provide some conditions on the allocation rule and the value function such that pairwise farsighted stability singles out the strongly efficient network. Finally, we have studied the relationship between pairwise farsighted stability and other concepts such as pairwise stability and the pairwise largest consistent set, a notion due to Chwe (1994). Under some conditions, a pairwise farsightedly stable set is a refinement of pairwise stability, which in turn is a refinement of the pairwise largest consistent set. By means of examples we have shown that there is no general relationship between (i) pairwise farsightedly stable sets and pairwise largest consistent sets, (ii) pairwise farsightedly stable sets and pairwise stability. Indeed, the pairwise stable networks may not belong to any pairwise farsightedly stable set of networks.

\section{Acknowledgments}

Vincent Vannetelbosch and Ana Mauleon are Research Associates of the National Fund for Scientific Research (FNRS). Vincent Vannetelbosch is Associate Fellow of CEREC, Facultés Universitaires Saint-Louis. Financial support from Spanish Ministerio de Ciencia y Tecnología under the project BEC 2003-02084, support from the Belgian French Community's program Action de Recherches Concertée 03/08-302 and 05/10-331 (UCL) and support of a SSTC grant from the Belgian Federal government under the IAP contract 5/26 are gratefully acknowledged. P. Jean-Jacques Herings would like to thank the Netherlands Organisation for Scientific Research (NWO) for financial support.

This paper presents research results of the Belgian Program on Interuniversity Poles of Attraction initiated by the Belgian State, Prime Minister's Office, Science Policy Programming. 


\section{References}

[1] Aumann, R., and R. Myerson, "Endogenous Formation of Links between Players and Coalitions: An Application of the Shapley Value," in The Shapley Value, A. Roth (ed.), Cambridge University Press, pp. 175-191 (1988).

[2] Bhattacharya, A., "Stable and Efficient Networks with Farsighted Players: The Largest Consistent Set," mimeo, University of York (2005).

[3] Calvó-Armengol, A., and Y. Zenou, "Social Networks and Crime Decisions: The Role of Social Structure in Facilitating Delinquent Behavior," International Economic Review 45, 939-958 (2004).

[4] Chwe, M.S., "Farsighted Coalitional Stability," Journal of Economic Theory 63, 299325 (1994).

[5] Dutta, B., S. Ghosal, and D. Ray, "Farsighted Network Formation," Journal of Economic Theory 122, 143-164 (2005).

[6] Dutta, B., and S. Mutuswami, "Stable networks," Journal of Economic Theory 76, 322-344 (1997).

[7] Herings, P.J.J., A. Mauleon and V. Vannetelbosch, "Rationalizability for Social Environments," Games and Economic Behavior 49, 135-156 (2004).

[8] Jackson, M.O., "The Stability and Efficiency of Economic and Social Networks," in B. Dutta and M.O. Jackson (eds.), Networks and Groups: Models of Strategic Formation, Springer-Verlag: Heidelberg (2003).

[9] Jackson, M.O., "A Survey of Models of Network Formation: Stability and Efficiency," in G. Demange and M. Wooders (eds.), Group Formation in Economics: Networks, Clubs and Coalitions, Cambridge University Press (2005).

[10] Jackson, M.O., and A. van den Nouweland, "Strongly Stable Networks," Games and Economic Behavior 51, 420-444 (2005).

[11] Jackson, M.O., and A. Watts, "The Evolution of Social and Economic Networks," Journal of Economic Theory 106, 265-295 (2002).

[12] Jackson, M.O., and A. Wolinsky, "A Strategic Model of Social and Economic Networks," Journal of Economic Theory 71, 44-74 (1996).

[13] Mauleon, A., and V. Vannetelbosch, "Farsightedness and Cautiousness in Coalition Formation Games with Positive Spillovers," Theory and Decision 56, 291-324 (2004). 
[14] Page, F.H., Jr., M. Wooders, and S. Kamat, "Networks and Farsighted Stability," Journal of Economic Theory 120, 257-269 (2005).

[15] Page, F.H., Jr., and M. Wooders, "Strategic Basins of Attraction, the Path Dominance Core, and Network Formation Games," Working Paper 05-W09, Department of Economics, Vanderbilt University (2005).

[16] Tercieux, O., and V. Vannetelbosch, "A Characterization of Stochastically Stable Networks," forthcoming in International Journal of Game Theory (2006).

[17] Watts, A., "A Dynamic Model of Network Formation," Games and Economic Behavior 34, 331-341 (2001).

[18] Watts, A., "Non-Myopic Formation of Circle Networks," Economics Letters 74, 277$282(2002)$.

[19] Xue, L., "Coalitional Stability under Perfect Foresight," Economic Theory 11, 603627 (1998). 